\title{
Communications
}

\section{That's My Bailiwick: A Library-Sponsored Faculty Research Web Server}

\author{
Paul A. Soderdahl and \\ Carol Ann Hughes
}

The University of Iowa Libraries provide a unique, new, scholarly publishing outlet for their faculty and graduate students. With the prevalence of personal faculty home pages and course Web sites in just about every department on campus, it's not very hard for faculty to find a Web server somewhere for storing an HTML file. And, with some work, faculty can often find some "techie" to help convert a document to HTML or to save a list of links.

What is rare, however, is a space on the Web where faculty from all disciplines can find a home for their scholarly research interests, coupled with a computing environment and a knowledgeable staff to help them "follow their bliss" in digital form. The Information Arcade's new Bailiwick project does just that.

\section{The Need for Something New}

For a number of years, academic departments in the humanities and social sciences have been able to mount departmental information on the University of Iowa's central Web server maintained by academic computing. More recently, two centrally administered course Web servers have been made available to any faculty member or teaching assistant offering a credit course. Based on feedback from faculty and graduate students, however, the university libraries learned that there was no place for a research idea or other academically oriented "pet project" to be published on the Web. Instead, faculty and students needed to bury these somewhere on a personal home page, often with a commercial Internet Service Provider at their own expense. Rising to address this need, the university libraries sought to provide a well-respected, institutionally supported Web server for just this sort of electronic publishing endeavor. What originally started as simply a "projects" directory on the library's general Web server has now grown into the Bailiwick project.

Officially launched in March 1998, Bailiwick provides a space on the Web where academic passions can be realized as highly specialized and creative Web sites. It is not simply a place for personal home pages, nor is it intended for course Web sites or academic departmental information. Rather, Bailiwick is designed to provide faculty, staff, and graduate students with Web space where they can focus on a particular area of scholarly interest.

Bailiwick is not meant to serve as the new model for scholarly publishing in peer-reviewed journals. Most electronic publishing initiatives arise from an attempt to transfer existing models of print publishing to the digital environment. A small number of electronic scholarly journals are currently published on the University of Iowa campus, and the university libraries already provide a number of ways to support this medium, from archiving to cataloging to hosting journal sites, as one element of the university libraries' new Scholarly Digital Resources Center.

Bailiwick, instead, provides a Web space that allows authors to harness and exploit this new electronic medium, permitting new models of expression with multimedia, hypertext, and the ability to incorporate anything in digital form. It is not intended to substitute or even compete with traditional scholarly publishing or electronic journal publishing. Rather, Bailiwick pro- vides an opportunity to engage in an entirely new medium for scholarly communication.

\section{A History of Innovation}

The heart of the Bailiwick Project within the library environment is the Information Arcade, an award-winning facility located in the University of Iowa's Main Library. Opened in 1992, the Information Arcade is a place that provides access to published electronic information resources coupled with state-of-theart multimedia development workstations that allow faculty and students to digitize and manipulate source materials that are not already in electronic form. The facility also houses a fully networked electronic classroom, with twenty-four student workstations, where classes from throughout the university are heldsome for the whole term and others for one or two class sessions.

In support of its unique service mission "to facilitate the integration of new technologies into teaching, learning, and research," the Information Arcade is well regarded as a place for innovation and risktaking on the University of Iowa campus. It is a place where ideas can be fleshed out; a place that can respond to the real technology needs presented by faculty and students. When the Information Arcade first opened, it was the only fully wired electronic classroom on campus, with a workstation at every student's desk. It was the only publicly accessible facility on campus where any faculty member or student

Paul A. Soderdahl (paul-soderdahl@ uiowa.edu) is Head of Information Arcade, and Carol Ann Hughes (carol-hughes@ uiowa.edu) is Head of Information, Research, and Instructional Services at the University of lowa Libraries. 
could create digital video on a dropin basis. It was the only computer facility on campus where anyone could access the Internet for free. All of these innovations are now mainstays on campus.

In 1998 the Information Arcade expanded its offerings with three new innovative Web-based services.

\section{The MOO Project}

This text-based virtual reality campus for the University of Iowa community is made possible through the magic of MOO, a piece of software that creates a networked environment on the Internet that is part e-mail, part chat-room, and part programming interface. Known collectively as "The Mediatrix," this educational MOO currently houses two distinct academic projects. The Scholar's Web Project, devoted to the possibilities of digital communication in graduate education, makes its MOO home in "The Cave." The MOOniversity Project, which strives to provide a virtual undergraduate learning environment that encourages collaboration across campuses and disciplines, is located in "The MOOniversity." Coadministered by D. Diane Davis, assistant professor of rhetoric in the rhetoric department, and Michael Calvin McGee, a professor of rhetoric in the communications studies department, the Mediatrix is available to any faculty member wishing to make use of either of them for teaching and research.

\section{The Streaming Video Project}

With text-based virtual reality at one end of the spectrum, the Information Arcade simultaneously launched a new streaming video server to meet high-end multimedia needs for delivering real-time motion video and audio over the Internet. With a fifty-user license to Real Networks'
Real Server, the Information Arcade now provides students and faculty with the ability to serve digital movie files to several locations simultaneously. Because of the streaming quality of the video files, users do not need to wait for an entire file to download before playing it. Already used by Bob Boynton, professor of political science, for his Multimedia Politics class, the streaming video server provides a delivery mechanism for the digital videos created by students and faculty at the Information Arcade's multimedia development stations.

\section{The Bailiwick Project}

By linking new modes of communication and providing an outlet for any number of innovative scholarly projects, the Bailiwick server has become a home for research projects, complementing the university libraries' course Web server. Space is available on this research Web server to any University of Iowa faculty, staff, or graduate student developing a scholarly academic Web site or Web-based tool that might be experimental in nature.

Open by simple proposal, Bailiwick runs on a dedicated Web server within the library and is supported by the university libraries' Web server infrastructure. Content providers retain editorial control and freedom, and have the ability to define their topic of interest, identify the target audience, and design a customized Web site. Each bailiwick is initially limited to $5 \mathrm{MB}$ of space, with the ability to petition for more based on specific needs for a given project. In addition to disk space, authors can turn to library staff at the Information Arcade for consultation on site design, graphics and layout, technical support, and training.

An individual bailiwick might:

- serve as a home page for artistic expression and collabora- tion among artists working in Iowa and other states;

- be a showcase for digitally produced art that incorporates interactivity meant to be viewed on a computer screen;

- provide a natural home for hypertext experiments that explore new forms of multilinear argument or open-system documents that welcome, even depend on, links to other Web sites to expand or counter those arguments;

- host a site not full of bells and whistles, but simply a collection of narrowly focused pages of links to resources on a given topic; and

- offer an electronic publishing medium for delivery of specialized bibliographies or digital reproductions of rare documents.

There are currently eleven bailiwicks in production, with another eight in development. The authors of bailiwicks represent thirteen different academic departments, including communication studies, political science, athletics administration, and theatre arts. They range in rank from teaching and research assistants to full professors.

\section{Sample Bailiwicks}

Currently, developed bailiwicks fall into one of four categories: (1) a collection of Internet links on a specialized topic of study, ranging from a small set of links on a particular page to an annotated Internet bibliography of thousands of links; (2) a hypertextual or multimedia essay or thesis that necessitates publishing in this medium; (3) a scholarly research project that is dynamic or updated with such frequency that print publishing would be ineffective, including, for example, ongoing findings from a research study; or (4) a collaborative project that makes use of a 


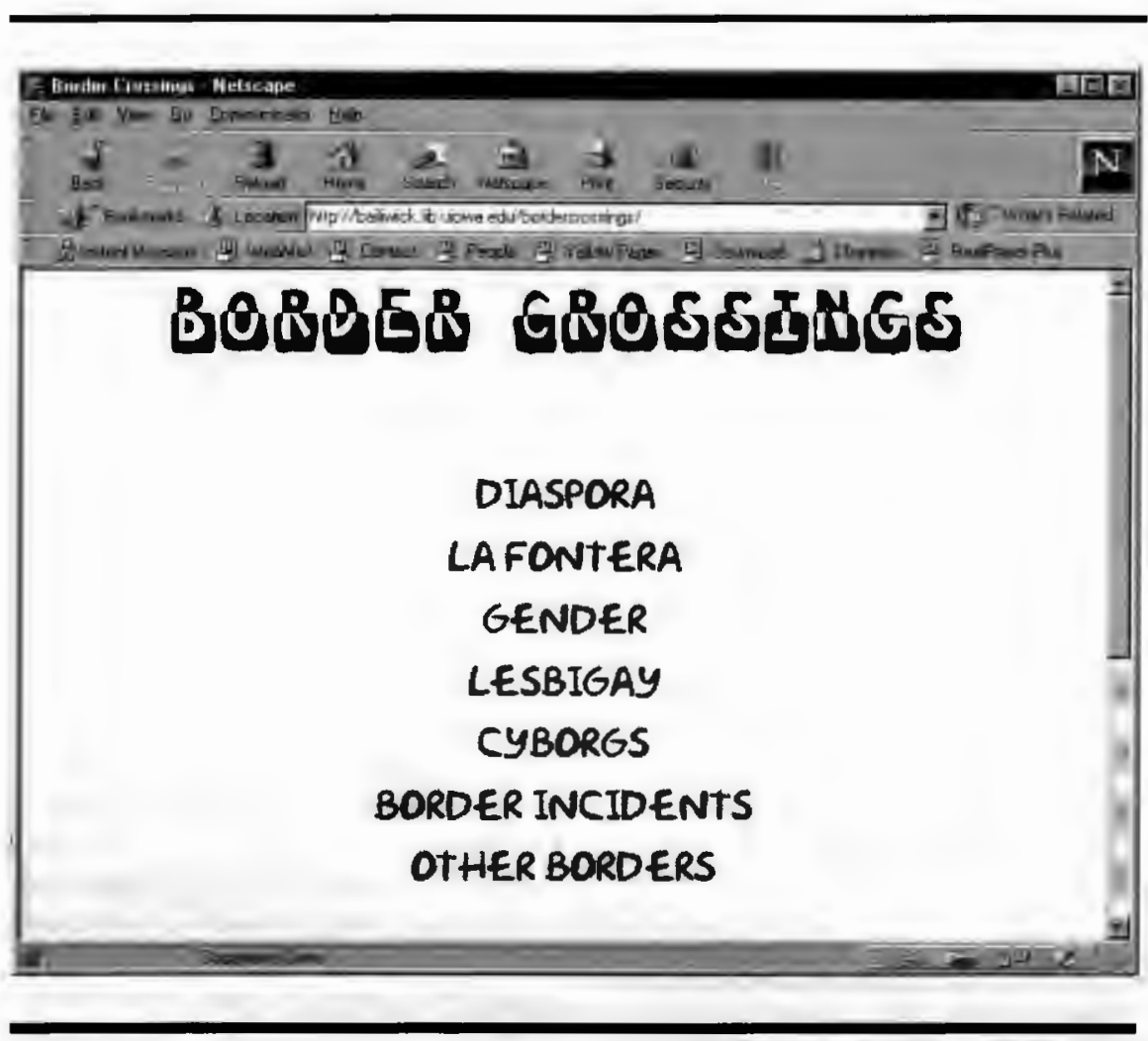

Figure 1. Karla Tonella's Award-Winning "Border Crossings" Bailiwick

shared electronically accessible work space.

\section{The Internet Bibliography}

Karla Tonella, a graduate student in mass communication, has authored three different bailiwick sites that loosely fall into the category of Internet bibliography. As a former graduate assistant and Information Arcade staff member, Tonella first identified the need for this sort of publishing medium on campus and articulated the concept of the Bailiwick project. She was instrumental in bringing the server to fruition and quickly adopted it as a home for two comprehensive and award-winning sites of Internet resources in her areas of expertise:
Online's catalog of recommended sites, and a feature article in Search, a monthly newsletter for advanced graduate students published by Northeastern University in Boston.

\section{The Multimedia Essay}

The most popular use for Bailiwick thus far has been for publishing multimedia essays. The Information Arcade itself has been a proponent of the multimedia essay since it first opened in 1992, and most semesterlong courses now held in the Information Arcade's electronic classroom incorporate some sort of multimedia term paper as part of the course requirements. The Information Arcade is one of the leaders on campus in the adoption of electronic theses and dissertations, working closely with the graduate college and academic computing on a pilot project this semester. It is not surprising, then, that faculty members and graduate students are turning to Bailiwick as a medium for publishing these sorts of materials.

Michael Calvin McGee, professor of communication studies, has published his essay, "Suffix it to Say that Reality is at Issue," as a bailiwick (see figure 2). Jennifer Lawrence-Gentry, a Ph.D. candidate also in communication studies, created a comprehensive site on the work of Mikhail Bakhtin, which is now seen as one of the most complete online resources on Bakhtin. Patrick Muller, a teaching assistant in preventive and community dentistry, developed a bailiwick essay titled, "Complexity Studies: The Fluid Multifaceted Nature of Knowledge." The sites are all very different in design, target audience, and perhaps even scholarly value. Nonetheless, Bailiwick provides an ideal way for the University of Iowa to support this sort of experimental multimedia publishing outside the rubric of a class assignment for a multimedia term paper or a 


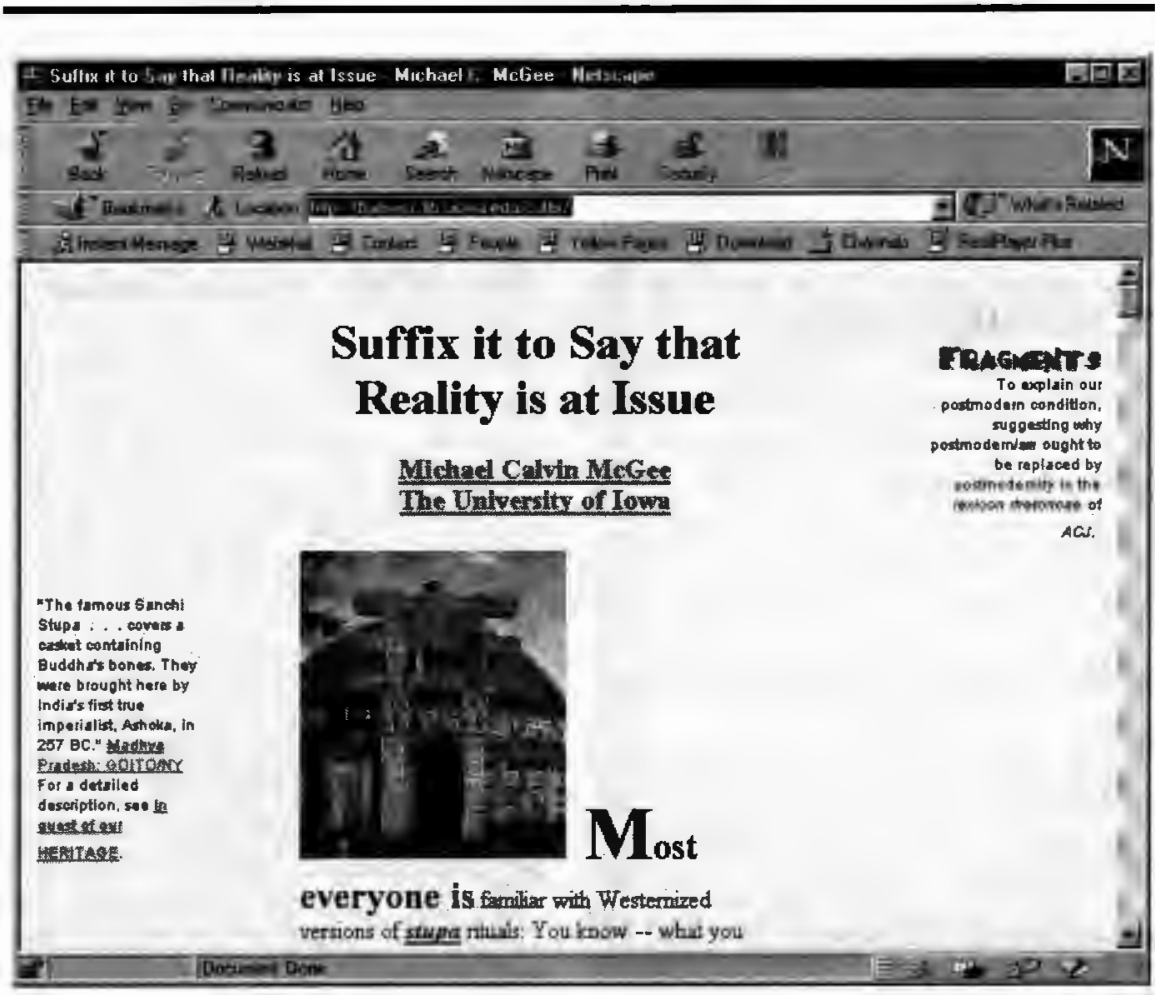

Figure 2. Professor Michael Calvin McGee's Essay Published as a Bailiwick

more traditional electronic scholarly publishing environment.

\section{The Scholarly Research Project}

Aside from the hypertextual and multimedia aspects of publishing on the Web, the most unique advantage to the Web for publishing scholarly research is the ability to maintain currency on a published project. The most well developed example of this is a bailiwick on gender equity in sports (see figure 3), sponsored by the women's intercollegiate athletics department. The site monitors the current state of affairs of gender equity in intercollegiate and interscholastic sport, and tracks Title IX compliance and pending Title IX litigation at colleges and universities. This resource into an SGML environment. It is an excellent example of an academic tool that would be difficult to create and deliver in paper form.

\section{The Collaborative Work Space}

The Bailiwick server provides a way for researchers at the University of Iowa to work collaboratively and in a public forum with colleagues at other institutions. This collaborative space can be used as a way to gather research data, or to allow others to comment on or contribute to the development of a site. Barbara Bianchi, a graduate student in counselor education and an art therapist, has established a bailiwick for Global Connections, a set of online art and notes from travel journals. One component of the Global Connections site, called "Russia Revisited," includes materials from a number of contributing artists and students in Russia, who are jointly working together to create a collaborative artistic travel journal.

International collaboration is being tested in another project as well. With grant funding, two scholars-one at the University of Iowa and one in Germany--are working with University of Iowa Libraries staff to create a new academic resource consisting of a Web-searchable critical edition of the work of Ingeborg Bachmann. This bailiwick will eventually contain bibliographies, a hypertext archive of materials not yet published in any form relating to Bachmann's life, work, and cultural context, and a searchable corpus of commentaries and translations. An advisory group for the project consisting of additional international scholars has already been named to oversee the development of content. As it grows, this bailiwick will result in an unprecedented resource for scholars from many disciplines. It presents a new 


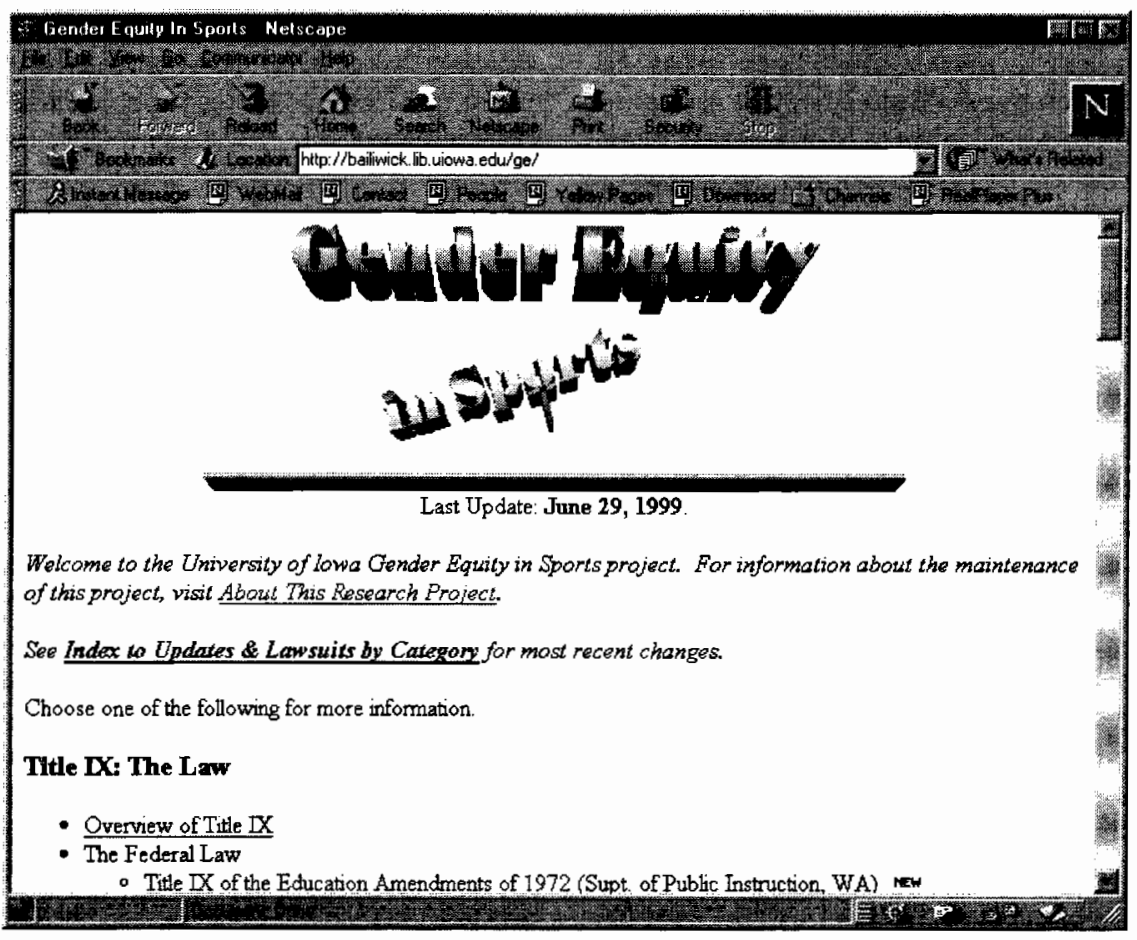

Figure 3. Bailiwick on Gender Equity in Sports Sponsored by the Women's Intercollegiate Athletics Department

model for the development of academic Web sites that not only reflect serious study but actually nurture the creation of new, international scholarships. Other Bailiwick proposals are also candidates for outside funding and can follow this exciting lead.

\section{Policies Regarding Bailiwick Sites}

Bailiwick sites run the gamut in subject area, nature, and scope. No attempt is made to centrally control the content of someone's site. After all, it is their bailiwick and they have complete editorial freedom. On the other hand, there are certain guidelines in place for establishing a bailiwick to maintain the focus of the project as an innovative research Web server.
First, the site is not intended to be a space for student class assignments. Short-term projects intended to meet course requirements can be accommodated currently on one of the university's centrally administered course Web servers. In addition, the site is not meant to be a place to mount a personal home page or even a student's career portfolio. This type of activity can be better accommodated on a student's personal account through academic computing or through a commercial Internet Service Provider. Sites that are commercial in nature are refused, as are sites that are completely divorced from the University's mission.

Content providers need to abide by the University's Acceptable Use Policy, which identifies inappropriate uses of information technology resources on campus, such as hack- ing, forgery, inserting viruses, violating intellectual property rights and software licenses, interfering with others' access to information technology resources, or personal campaigning, lobbying, or commercial activities.

These modest restrictions notwithstanding, most proposals for bailiwicks have been approved. Inappropriate use of bailiwick Web space has not yet been an issue.

\section{Library Resources to Support the Project}

The hallmark of the Information Arcade is its dual strength in providing a facility with state-of-the-art, high-end computing equipment for electronic publishing and multimedia development as well as providing a diverse public services staff who can work closely with faculty and students, often one-on-one, to help them harness the technology and integrate it effectively into their teaching, learning, and research. The facility is staffed with six half-time graduate assistants selected from a variety of academic programs in an attempt to achieve a balance of technologists, information specialists, graphics artists, and instructional designers. The primary benefit of this unique staffing arrangement is that the Information Arcade is much more than just another computer or library lab. It is a place where faculty and students can find qualified consultants trained in a subject specialty with expertise in almost any area related to technology.

With this high-tech and hightouch model, the Information Arcade is uniquely suited to host a project like Bailiwick. Within the walls of this facility, the library provides support for every step of development from inception to creation to delivery. With expert consultation, access to equipment, technical support, and Web server space, the Arcade becomes a 
one-stop place for presenting scholarly research.

Staff support includes consultation in any aspect of the Bailiwick project, including design issues, interface development, and training in software. Staff members do not provide programming nor do they do any work in researching or assembling sites. Each faculty member is assigned an Information Arcade consultant at the point of submitting a bailiwick application. The consultant serves as a primary contact person for technical support, troubleshooting, basic interface design guidance, and referrals to other staff both in the libraries and on campus. At present, the current level of staffing has been sufficient to accommodate this sort of assistance, which is not unlike the assistance provided to any patron who walks in the door of the Information Arcade.

As a computing facility, the Information Arcade provides public access to a host of multimedia development workstations for scanning images, slides, and text, and for digitizing video and audio. At these multimedia stations, a large suite of multimedia integration software and Web publishing software is made available for public use. Staff at the public services desk have a strong background in multimedia development and Web design and can provide some one-on-one training on a walk-in basis beyond technical support and troubleshooting. All of these hardware and software resources are available to Bailiwick content providers, who can choose to do their development work in the Information Arcade or at their home or office.

Finally, since there is a close relationship between the Information Arcade and the university libraries Web site, system administration and Web server support is all handled inhouse as well. There are few artificial barriers imposed by the technology, thereby permitting content providers to focus on their creative expression and scholarly work.
With only minimal reallocation of existing resources, the University of Iowa Libraries has been able to launch the Bailiwick project and continue to develop it at a modest pace. One of the components most essential for its continued success, howev$\mathrm{er}$, is the ability to scale up to meet the expected demand over the next several years. Technical infrastructure challenges are not overwhelming as yet. An analysis still needs to be made to determine how quickly creators are developing their sites, what the implications are for network delivery of these resources, what reasonable projections there are for disk space, and who is using the resources.

Perhaps more importantly, though, adequate staffing will always remain a concern. Some faculty wish to work more closely with library staff consultants than time allows, and the consultants would certainly find it enriching to be more intimately involved with the development of each bailiwick site. Marketing of the Bailiwick project has been discrete (to say the least) because of the limited staffing available. However, embedded in the collaboration inherent in bailiwicks is the potential for stronger involvement with faculty in obtaining grant funding to support the development of specific bailiwick sites.

\section{A Model for Research Libraries}

Bailiwick is a project that allows the University of Iowa Libraries, and specifically the Information Arcade, to focus on the integration of technology, multimedia, and hypertext in the context of scholarship and research. To date, most of the bailiwick sites represent disciplines in the arts, humanities, and social sciences. This matches the overall clientele of the Information Arcade (given its location in the University of Iowa's Main Library), but it also reflects the fact that these disciplines have been tradi- tionally undersupported with respect to technology. Nevertheless, individual faculty in these disciplines have integrated some of the most creative applications of the technology in their everyday teaching and research, in part because of the existence of the Information Arcade and the groundwork laid by the libraries for the past several years.

With the Information Arcade's visibility on campus, and with similar resources and support in the Information Commons - a sister facility in the Hardin Library for the Health Sciences-the University of Iowa Libraries are well regarded on campus as a leader in information technology, electronic publishing, and new media. Thus, faculty and students alike are accustomed to turning to the libraries for innovation in technology and the Bailiwick project is a natural fit. Bailiwick is now fully integrated as part of a palette of new technology services and scholarly resources included within the libraries' support of teaching, learning, and research at the University of Iowa.

\section{Engelond: A Model for Faculty-Librarian Collaboration in the Information Age}

\section{Scott Walter}

The question of how best to incorporate information literacy instruction into the academic curriculum has long been a leading concern of academic librarians. In

Scott Walter (walter.123@osu.edu), formerly Humanities and Educaton Reference Librarian, University of Missouri-Kansas City, now is Information Services Librarian, Ohio State University. 